\title{
SKIRTINGŲ KINEZITERAPIJOS VEIKSNIŲ POVEIKIS RAUMENU FUNKCIJOMS IR AEROBINIAM METABOLIZMUI, ESANT APATINĖS NUGAROS DALIES STUBURO IŠVARŽAI
}

\author{
Domas Trinkūnas, Rūta Dadelienè \\ Vilniaus universiteto Medicinos fakulteto Sveikatos mokslu institutas
}

Raktažodžiai: stuburo slankstelio išvarža, raumenų aktyvumas, aerobinis metabolizmas.

\begin{abstract}
Santrauka
Tyrimo tikslas - įvertinti skirtingų kineziterapijos veiksnių poveikị raumenų funkcijoms ir jų aerobiniam metabolizmui, esant apatinès nugaros dalies stuburo išvaržai. Tyrimo metodai. Tyrime dalyvavo 38 asmenys, turintys apatinès nugaros dalies stuburo išvaržą. Prie paskirtos 20 minučių trukmès kineziterapijos programos papildomai I grupès ( $\mathrm{n}=19)$ dalyviams buvo skiriami 20 minučių trukmès dinaminiai pratimai, o II grupès $(\mathrm{n}=19)$ dalyviams buvo skiriami 20 minučiu trukmès statiniai pratimai, turintys biologini grịžtamaji ryši. Abiejų grupių treniravimo programos truko šešias savaites, tris kartus per savaitę. Tyrimo metu buvo vertintas raumenų aerobinis metabolizmas, naudojant „Moxy“ raumenų oksimetrą, raumenų issitempimo lygis, naudojant „Kinesis“ elektromiografijos prietaisą. Raumenų funkcijos vertintos išmatavus pasiekiamą judesio amplitudę, amplitudžių matuokliu „Mobee Med“, bei atstumas nuo mentès vidinio krašto iki stuburo keteros vidurio taško, buvo vertinamas centimetrine juostele. Duomenų analizè atlikta naudojant statistinès analizės Microsoft Excel 2016 ir IBM SPSS Statistics 25 programas.

Tyrimo rezultatai. Judesių amplitudès asimetrijos sumažejimas buvo stebimas tik po dinaminių pratimų programos $(\mathrm{p}<0.001)$. Dinaminių pratimų grupejje raumens aktyvumo asimetrija sumažejo tik viduriniame trapeciniame raumenyje $(\mathrm{p}<0,05)$, o statinių pratimų, turinčių biologini grịžtamajị ryši, grupejje raumens aktyvumo skirtumas sumažejo viduriniame trapeciniame, bei didžiajame sẻdmens raumenyse. Statinių pratimų, turinčių biologini grižtamuajji ryšị, programa daugiau sumažino didžiojo sẻdmens raumenų deguonies kiekio disbalansą $(\mathrm{p}<0,001)$, nei dinaminių pratimų programa.
\end{abstract}

Išvados. Dinaminių kineziterapijos pratimų programa turejjo reikšmingą poveiki judesių amplitudžių asimetrijos sumažèjimui. Statinių kineziterapijos pratimų, turinčių biologini grįžtamaji ryšį, metodika daugiau padidino bendrą raumens aktyvumą ir labiau sumažino raumenų aktyvumo asimetriją, nei dinaminiai kineziterapijos pratimai. Statinių kineziterapijos pratimų, turinčių biologinį grịžtamajị ryši, metodika daugiau sumažino raumens aerobinio metabolizmo disbalansą tarp raumens kairiosios ir dešiniosios pusių, nei dinaminių kineziterapijos pratimų naudojimas.

\section{Ivadas}

Apatinès nugaros dalies skausmas pasireiškia 85 proc. visų žmonių bent vieną kartą gyvenime [1]. Šis skausmas gali atsirasti dèl raumenų pervargimo, bet sunkesniais atvejais jis pasireiškia esant stuburo išvaržai. Esant apatinès stuburo dalies išvaržai, neretai spaudžiamas arba kitaip dirginamas iš nugaros smegenų išsišakojantis nervas. Pagrindiniai simptomai: nugaros skausmas, vienos kojos skausmas, skausmo plitimas žemiau kelio srities, sumažèjusi paveiktos kojos raumenų jèga bei sumažeję̨s jos sensorinis jautrumas [2]. Stuburo tarpslankstelinio disko išvarža (TDI) nustatoma 2-3 proc. visos populiacijos, dažniausiai apie 37 gyvenimo metus [2]. Asmenims, kurių skausmas didesnis ir pastovesnis, prognozės dažniausiai prastesnès, tokie pacientai sunaudoja daugiau sveikatos sistemos išteklių, yra ilgiau neveiklūs ir ilgiau negrịžtanta ị darbinę veiklą [3]. 90 proc. pacientų, turinčių TDI, skiriamas konservatyvusis gydymas [4]. Gerinti pacientų raumenų aktyvumą pasitelkiamos modernios reabilitacijos technologijos. Elektromiografijos (EMG) suteikiamas biologinis grižtamasis ryšys (BGR) bei raumens deguonies kiekio $\left(\mathrm{SmO}_{2}\right)$ nustatymas yra nauji ir specializuoti metodai [5]. Šie metodai naudojami kartu su jau žinomais: pratimų rūšys, trukmè ir apkrovos kiekis. Kyla mokslinė problema - ieškoti metodų ir priemonių, kurios efektyviau pagerintų asmenų, turinčių TDI, raumenų funkcijas. Nėra 


\section{2}

atlikta daug tyrimų, nagrinėjančių kombinuoto statinių pratimų ir biologinio grižtamojo ryšio metodo poveikị pacientu raumenims, esant TDI.

Tyrimo tikslas - įvertinti skirtingų kineziterapijos metodų poveikį raumenų funkcijoms ir jų aerobiniam metabolizmui, esant apatinès nugaros dalies stuburo išvaržai.

\section{Tyrimo medžiaga ir metodai}

Tyrimo vieta - kineziterapijos stuburo ir sveikatingumo centras. Tyrimo laikotarpis 2019-2020 metai. Tyrimo objektas - dinaminiai ir statiniai fiziniai pratimai. Tyrime dalyvavo 24 vyrai $(42,54 \pm 9,13 \mathrm{~m}$.) ir 14 moteru $(36,86 \pm 7,76$ m.). Testuoti 38 tiriamieji (1 tyrimas), po to atsitiktiniu būdu suskirstyti ị dvi tiriamąsias grupes: pirmoji dinaminių jẻgos treniruočių grupè ( 1 grupè, $n=19)$, antroji - statinių jègos treniruočių grupè (2 grupe், $n=19)$. Tyrimo dalyvių atrankos kriterijai atskleisti 1 lentelëje.

Tyrimo metu buvo vertinami didysis sėdmens raumuo ir vidurinis trapecinis raumuo. Abiejų grupių tiriamieji šešias savaites, 3 kartus per savaitę po 20 minučių atliko jiems paskirtos kineziterapijos programą. Po jos 1 grupei buvo skiriami 20 minučių dinaminiai pratimai su 60 proc. nuo maksimalaus pajėgumo apkrova [6]: menčių suvedimas, rankos ir priešingos kojos kèlimas ị viršų, klūpant ant keturių ir kiti. 2 grupès tiriamiesiems 20 minučių buvo skiriama statinių jẻgos pratimų treniruotè, naudojant „Kinesis“ elek-

1 lentelè. Tyrimo dalyvių atrankos kriterijai

\begin{tabular}{|l|l|}
\hline Itraukimo & Atmetimo \\
\hline $\begin{array}{l}\text { Amžius nuo 25 iki 55 } \\
\text { metų }\end{array}$ & Nesutikimas dalyvauti tyrime \\
\hline $\begin{array}{l}\text { Apatinės nugaros dalies } \\
\text { stuburo išvarža }\end{array}$ & Širdies ir kraujagyslių sistemos ligos \\
\hline & Gretutinès judejimo sistemos ligos \\
\hline & Ummi nugaros skausmo stadija \\
\hline & $\begin{array}{l}\text { Vartojami skausmą mažinantys me- } \\
\text { dikamentai }\end{array}$ \\
\hline & $\begin{array}{l}\text { Taikytas juosmeninės stuburo dalies } \\
\text { operacinis gydymas }\end{array}$ \\
\hline
\end{tabular}

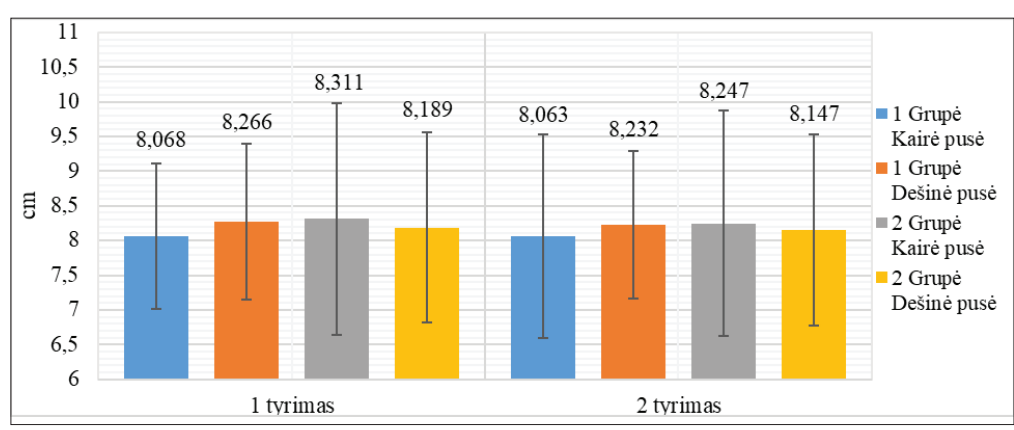

1 pav. Atstumas nuo mentės vidinio krašto iki stuburo keteros tromiografijos aparatą. Tiriamieji turèjo įtempti raumenį ir 20 sekundžių išlaikyti įsitempimo lygị 40-60 proc. nuo galimo maksimalaus izometrinio įsitempimo lygio. Po 20 sekundžiu darbo, 10 sekundžių raumuo buvo visiškai atpalaiduojamas. Iš viso buvo atliekama 10 pakartojimų be sustojimo.

Raumens ịsitempimo lygis buvo matuojamass „Kinesis“ prietaisu $(\mu \mathrm{V})$. Tiriamojo raumens suformuojamo elektrinio impulso stiprumas realiu laiku buvo atvaizduojamas tiriamajam matomame kompiuterio ekrane. Ant tiriamojo raumens buvo pritvirtinami du elektrodai matuoti raumens įsitempimo lygị ir vienas papildomas, bet kurioje kūno vietoje. Jo funkcija - sumažinti ị teigiamą ir neigiamą elektrodus gaunamus šalutinius signalus. Tyrimo metu tiriamasis siekia išlaikyti raumens ịsitempimo lygị nuo 40 iki 60 proc. nuo pasiekto maksimalaus įsitempimo lygio.

Raumenų funkcijos - judesių amplitudès buvo nustatomos skaitmeniniu amplitudžių matuokliu „Mobee Med“ (laipsniais). Tyrimo metu įvertinama judesio amplitudè, keliant koją i viršų, klūpint keturiomis, kai rankos per alkūnės sąnarị ištiestos. Atstumas nuo menčių vidinio krašto iki stuburo keteros vidurio taško matuojamas centimetrine juostele $(\mathrm{cm})$.

Raumens aerobinis metabolizmas nustatomas introskopijos būdu, raumenų oksimetru „Moxy“. Tyrimo metu prietaiso daviklis tiesiogiai uždedamas ant odos ties tiriamojo raumens galva. „Moxy“ oksimetras raumens ịsitempimo metu matuoja raumens deguonies prisotinimo (oksigenacijos, $\mathrm{SmO}_{2}$ ) procentinę išraišką.

Statistinè duomenų analizė atlikta Microsoft Excel 2016 ir IBM SPSS Statistics 25 programomis. Patikrintas tyrimo duomenų normalumo lygmuo Shapiro-Wilk testu. Apskaičiuoti gautų tyrimo rezultatų vidurkiai, standartiniai nuokrypiai. Rezultatų reikšmingumo lygmuo $(\mathrm{p}<0,05)$ vertinamas Wilcoxon kriterijumi ir Student $t$ testu.

\section{Tyrimo rezultatai}

Pamatavus atstumą nuo tiriamujų mentès vidinio krašto iki stuburo keteros, antrojo tyrimo metu abiejose grupèse statistiškai reikšmingų pokyčių nebuvo. Apskaičiavus atstumo nuo mentès vidinio krašto iki stuburo keteros skirtumo pokyčius prieš ir po taikomos treniruočių programos, statistiškai reikšmingas pokytis buvo stebimas tik 1 grupeje $(\mathrm{p}<0,001)$ (1 pav.).

Vertinant tiriamujų kojos tiesimo atgal amplitudžių pokyčius, statistiškai reikšmingas padidejjimas buvo stebimas tiesiant kairiąą koją pirmoje $(\mathrm{p}=0,009)$ ir antroje $(\mathrm{p}=0,002)$ grupèse. Statistiškai reikšmingas pasiekiamos amplitudès skirtumo sumažèjimas 
buvo tik pirmoje grupejje ( $\mathrm{p}=0,001)$ ( 2 pav.).

Vertinant tiriamujų vidurinio trapecinio raumens aktyvumą buvo nustatyta, kad po treniruočiu programos abiejose grupèse tiriamuju vidurinis trapecinis raumuo buvo statistiškai reikšmingai aktyvesnis $(p<0,05)$. Antros grupès raumens aktyvumo skirtumo tarp kairiosios ir dešiniosios pusių sumažėjimas buvo statistiškai reikšmingai didesnis, nei pirmosios $(\mathrm{p}=0,028)$. Šie duomenys parodo, kad antrai grupei taikyta statinių pratimų su BGR programa buvo efektyvesne, nei pirmoje grupeje taikyta dinaminiu pratimų programa (3 pav.).

Vertinant pirmos grupès tiriamujų didžiojo sèdmens raumens aktyvumą buvo nustatyta, kad po dinaminių pratimų treniruočių programos ciklo statistiškai reikšmingas aktyvumo padidejimas buvo tik raumens kairiojoje puseje $(\mathrm{p}=0,003)$. Raumens aktyvumo skirtumo tarp kairiosios ir dešiniosios pusių sumažèjimas statistiškai reikšmingo skirtumo nesudarè $(\mathrm{p}=0,098)$. Antroje grupeje po statinių pratimu su BGR metodo taikymo, statistiškai reikšmingas raumens aktyvumo padidejjimas buvo stebimas abiejose raumens pusėse $(p<0,05)$. Antroje grupeje aktyvumo skirtumas tarp kairiosios ir dešiniosios raumens pusių statistiškai reikšmingai sumažejo ( $\mathrm{p}=0,001)$, (4 pav.). Abieju grupių gautų rezultatų palyginimas parodè, kad tik po statinių pratimų su BGR metodo taikymu, abiejose raumens pusèse padidejjo raumens aktyvumas bei sumažejo raumens kairiosios ir dešiniosios pusių aktyvumo skirtumas.

Matuojant pirmos grupes tiriamųjų deguonies kiekị viduriniame trapeciniame raumenyje buvo nustatyta, kad po treniruočių programos ciklo nebuvo statistiškai reikšmingo deguonies kiekio pokyčio $(p>0,05)$. Šioje grupejje buvo stebimas statistiškai reikšmingas deguonies kiekio skirtumo sumažėjimas tarp abiejų raumens pusių $(p<0,001)$. Pirmojo tyrimo metu raumens deguonies skirtumas sieke $9,21 \pm 4,29$ proc. $\mathrm{SmO}_{2}$, po antrojo tyrimo sumažèjo iki $6,24 \pm 4,71$ proc. $\mathrm{SmO}_{2}$. Antroje grupeje po statinių pratimų taikant BGR metodą, buvo stebimas statistiškai reikšmingas deguonies kiekio padidejjimas kairiojoje $(\mathrm{p}=0,022)$ ir dešiniojoje $(\mathrm{p}=0,003)$ pusèse. Šioje grupeje buvo stebimas statistiškai reikšmingas deguonies kiekio skirtumo sumažejimas tarp kairiosios ir dešiniosios vidurinio trapecinio raumens pusių $(\mathrm{p}<0,001)$ (5 pav.). Pirmojo tyrimo metu deguonies skirtumas buvo $10,38 \pm 4,48$ proc. $\mathrm{SmO}_{2}$, o antrojo - sumažèjo iki $3,75 \pm 1,97$ proc. $\mathrm{SmO}_{2}$.

Pamatavus abiejų grupių didžiojo sėdmens raumens deguonies kiekị buvo nustatyta, kad po treniruočių programos ciklo statistiškai reikšmingo pokyčio nebuvo, tačiau, paskaičiavus abiejų grupių deguonies kiekio skirtumą tarp kairiosios ir dešiniosios raumens pusių, nustatytas statistiškai reikšmingas skirtumo sumažejjimas ir pirmoje $(\mathrm{p}=0,004)$, ir antroje $(\mathrm{p}=0,000)$ grupèse. Pirmoje grupeje po dinaminių pratimų metodo taikymo raumens deguonies skirtumas tarp abiejų raumenų pirmojo tyrimo metu sieké 7,80 $\pm 7,47$ proc. $\mathrm{SmO}_{2}$, o antrojo tyrimo metu sumažèjo iki $4,44 \pm 3,11$ proc. $\mathrm{SmO}_{2}$. Antroje grupejje statinių pratimų, taikant BGR metodą, poveikis statistiškai reikšmingai skirtumą sumažino daugiau, nei pirmosios grupès taikytas poveikis $(\mathrm{p}=0,037)$. Antroje grupeje pirmo tyrimo metu deguonies

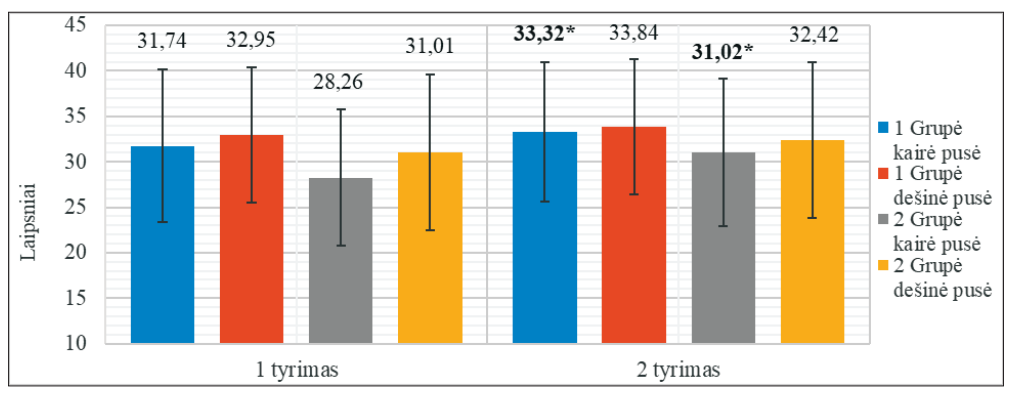

2 pav. Kojos tiesimo atgal amplitudžių kaita $(*-p<0,05)$

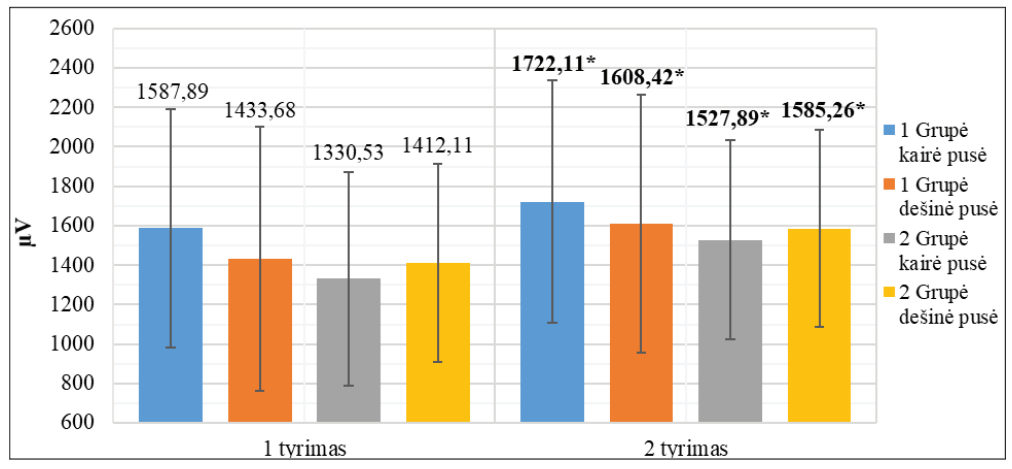

3 pav. Vidurinio trapecinio raumens aktyvumas $(*-\mathrm{p}<0,05)$

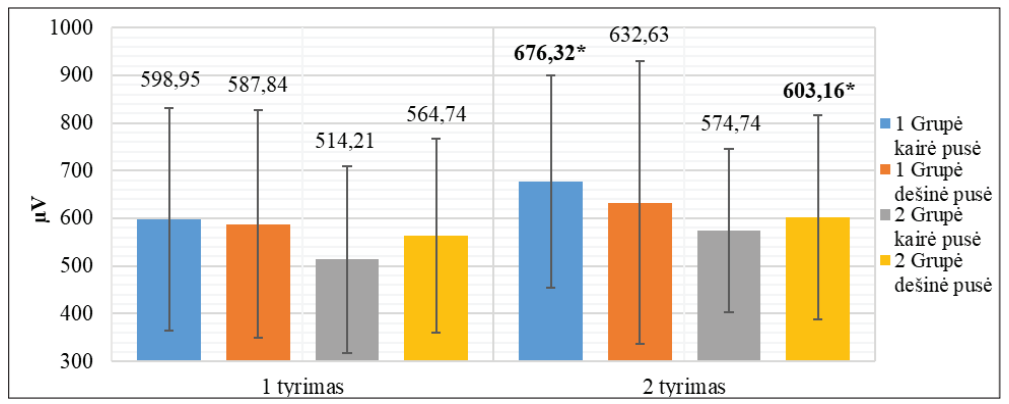

4 pav. Didžiojo sėdmens raumens aktyvumas $(*-p<0,05)$ 
skirtumas tarp abiejų raumens pusių buvo $7,21 \pm 4,09$ proc. $\mathrm{SmO}_{2}$, o antrojo - sumažejo iki $2,67 \pm 1,73$ proc. $\mathrm{SmO}_{2}$ (6 pav.). Statinių pratimų su BGR naudojimas buvo statistiškai reikšmingai efektyvesnè priemonè, mažinant deguonies kiekio skirtumą tarp abiejų raumens pusių.

\section{Diskusija}

Tyrejai pastebi, kad pacientų, turinčių apatinès nugaros dalies tarpslankstelinio disko išvaržą, pilvo, juosmens ir sẻdmenų raumenų aktyvumas yra mažesnis nei asmenų, neturinčių šios patologijos [7]. Mūsų atliktame tyrime buvo stebimas abiejų grupių vidurinio trapecinio raumens statistiškai reikšmingas aktyvumo padidejjimas. Šio raumens aktyvumas labiau didejo taikant statinius pratimus su BGR, nei dinaminius. Kito tyrimo, kuriame EMG teikiamas BGR naudotas kaip treniravimo priemoné, rezultatai taip pat parode padidejusị vidurinio trapecinio raumens aktyvumą [8]. Mūsų atliktame tyrime statinių pratimų su BGR grupeje buvo stebimas didesnis raumens aktyvumo asimetrijos sumažejimas tarp abiejų raumens pusių, nei dinaminių pratimų grupeje. Tiriant vidurinio trapecinio raumens aerobinị metabolizmą buvo pastebèta, kad tik atliekant statinius pratimus su BGR, gautas statistiškai reikšmingas pokytis. Izometrinių pratimų su BGR programos grupejje deguonies kiekio skirtumas tarp abiejų raumens pusių sumažèjo daugiau, nei dinaminių pratimų programoje. Literatūroje pastebima, kad pacientų, turinčių apatinès nugaros dalies patologiją, didesnè bendro didžiojo sẻdmens raumens masès bei raumens aktyvumo sumažèjimo rizika, lyginant su sveikais asmenimis [9]. E. Skorupska su kolegomis atliktame tyrime nustate, kad didžiojo sèdmens raumens mase ir raumens aktyvumas buvo mažesni

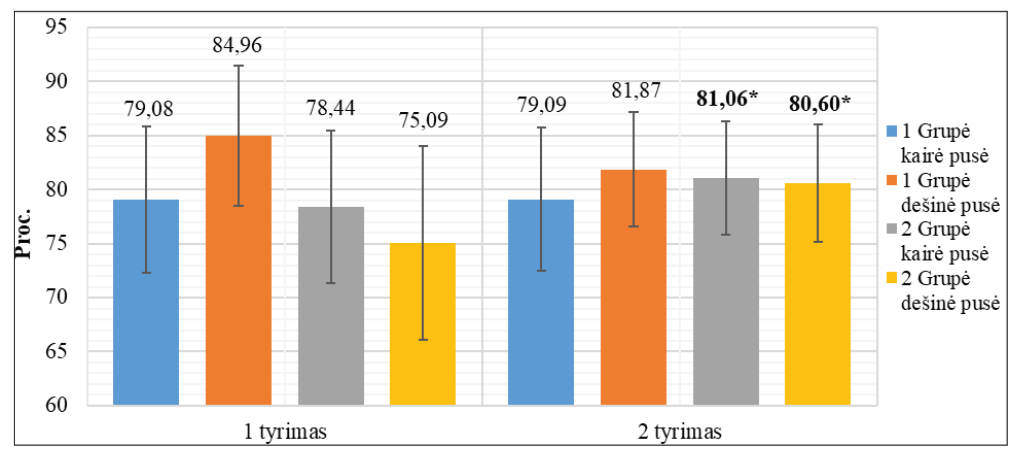

5 pav. Vidurinio trapecinio raumens deguonies kiekis $\left(\mathrm{SmO}_{2}\right)$

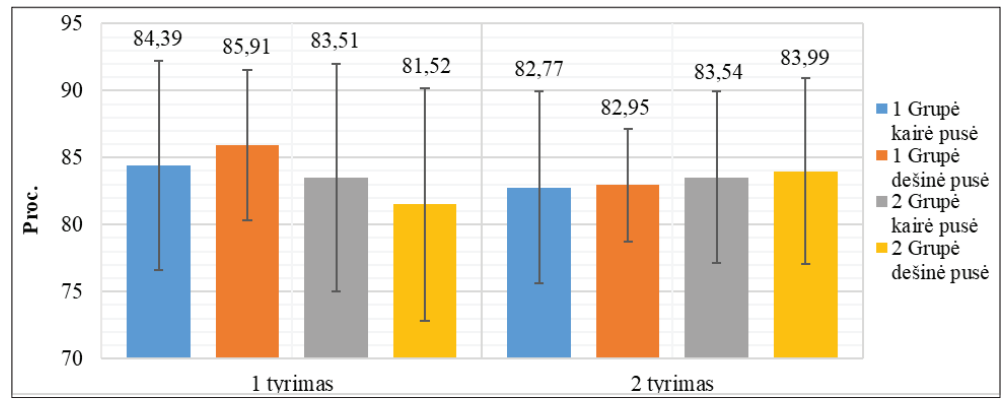

6 pav. Didžiojo sėdmens raumens deguonies kiekis $\left(\mathrm{SmO}_{2}\right)$ toje puseje, kurioje pacientas jautè skausmą. Tiriant šị raumení, pastebètas greitesnis raumens nuovargio atsiradimas, nei sveikų asmenų [10]. Mūsų atliktame tyrime didžiojo sèdmens raumens aktyvumas po dinaminių pratimų programos statistiškai reikšmingai padidejo raumens kairiojoje puseje, o po statinių pratimų programos - dešiniojoje raumens pusèje. Vertinant šio raumens aktyvumo asimetriją, statistiškai reikšmingas aktyvumo skirtumo tarp kairiosios ir dešiniosios raumens pusių sumažejimas buvo stebimas tik po statinių pratimų su BGR programos. Tiriamiesiems, kuriems buvo taikoma izometrinių pratimų su BGR programa, didžiojo sẻdmens raumens deguonies lygio skirtumas tarp abiejų raumens pusių sumažèjo daugiau, nei tiriamiesiems, kuriems buvo paskirta dinaminių pratimų programa.

A. Bertotto ir kolegų atliktame tyrime palygintas dubens dugno raumenų pratimų efektyvumas su ir be EMG suteikiamo BGR. Po pratimų programos tiriamųų grupeje, kurioje pratimai buvo atliekami taikant BGR, maksimalus raumens ịsitempimo lygis buvo 37,5 proc. didesnis nei grupeje, kurioje dubens dugno pratimai buvo atliekami be BGR $(p<0,0001)$ [11].

\section{Išvados}

1. Dinaminių kineziterapijos pratimų programa turejo reikšmingą poveikị judesių amplitudžių asimetrijos sumažejjimui.

2. Statinių kineziterapijos pratimų su biologiniu grịžtamuoju ryšiu metodika daugiau padidino bendrą raumens aktyvumą ir labiau sumažino raumenų aktyvumo asimetriją, nei dinaminiai kineziterapijos pratimai.

3. Statinių kineziterapijos pratimų su biologiniu grịžtamuoju ryšiu metodika daugiau sumažino raumens aerobinio metabolizmo disbalansą tarp raumens kairiosios ir dešiniosios pusių, nei dinaminių kineziterapijos pratimų taikymas.

\section{Literatūra}

1. Alfuth M, Welsink DW. Pain and functional outcomes after outpatient physiotherapy in patients with low back pain. Der Orthopäde 2017;46:522-529.

https://doi.org/10.1007/s00132-017-3390-x 
2. Vialle LR, Vialle EN, Esteban J, Henao S, Giraldo G. Lumbar disc herniation. Rev Bras Ortop 2010;45(1):17-22. https://doi.org/10.1590/S0102-36162010000100004

3. Verhagen AP, Downie A, Popal N, Maher C. Red flags presented in current low back pain guidelines: a review. Eur Spine J 2016; 25:2788-2802. https://doi.org/10.1007/s00586-016-4684-0

4. Abu-Naser SS, Aldahdooh R. Lower back pain expert system diagnosis and treatment. J Multidisc Engin Sc Studies 2016;2(4):441-6.

5. Larsson B, Dragioti E, Grimby-Ekman A, Gerdle B, Björk J. Predictors of chronic pain intensity, spread, and sensitivity in the general population: a two-year follow-up study from the SWEPAIN cohort. J of Rehab Med 2019;51(3):183-192. https://doi.org/10.2340/16501977-2519

6. Ratamess NA, Alvar BA, Evetoch TK. Progression models in resistance training for healthy adults. American college of sports medicine. Med Sci Sports Exerc 2009;41:687-708.

https://doi.org/10.1249/MSS.0b013e3181915670

7. Ji-Hyun M, Seung-Jin P, Yun-A S. The effects of the use of pilates equipment during pilates hundred, swimming exercise on the muscle activation of abdominal muscles, lumbar erector spinae, gluteus of lumbar disc disease patients. Exerc Sci 2019;28(1):41-8.

https://doi.org/10.15857/ksep.2019.28.1.41

8. San JG, Gunderson SR, Kane-ronning K, Suprak DN. Scapular kinematic is altered after electromyography biofeedback training. J Biomech 2016;49:1881-1886.

https://doi.org/10.1016/j.jbiomech.2016.04.036

9. Amabile AH, Bolte JH, Richter SD. Atrophy of gluteus maximus among women with a history of chronic low back pain. PLoS One 2017;12(7):1-12.

https://doi.org/10.1371/journal.pone.0177008

10. Skorupska E, Keczmer P, Łochowski RM, Tomal P, Rychlik M, Samborski W. Reliability of MR-based volumetric 3-D analysis of pelvic muscles among subjects with low back with leg pain and healthy volunteers. PLoS One 2016;11(7):1-15. https://doi.org/10.1371/journal.pone.0159587

11. Bertotto A, Schvartzman R, Uchôa S, Celeste M, Wender O. Effect of electromyographic biofeedback as an add-on to pelvic floor muscle exercises on neuromuscular outcomes and quality of life in postmenopausal women with stress urinary incontinence : a randomized controlled trial. Neulol \& Urodyn 2017;36-8:1242-1247.

https://doi.org/10.1002/nau.23258

\section{EFFECT OF DIFFERENT PHYSICAL THERAPY FACTORS ON MUSCLE FUNCTION AND AEROBIC METABOLIZM IN PATIENTS WITH LUMBAR DISC HERNIATION \\ D. Trinkūnas, R. Dadelienè}

Keywords: aerobic metabolism, muscle activity, lower back pain, spinal hernia.

Summary

Aim of research work: to evaluate the effects of different physiotherapy methods on muscle function and aerobic metabolism in patients with lower back hernia.

Subjects and methods: the study included 38 individuals with lower back hernia. In addition to the assigned 20-minute physiotherapy program, participants in group I $(n=19)$ received 20 minutes of dynamic exercise, and participants in group II $(n=19)$ received 20 minutes of static exercise with biological feedback. Treatment programs for both groups lasted six weeks, three times a week. Muscle aerobic metabolism was measured by "Moxy "muscle oximeter and muscle activity level was measured using "Kinesis" electromyography device. Muscle function was assessed by measuring the range of motion using the "Mobee Med" amplitude meter and the distance from the inner edge of the shoulder blade to the midpoint of the ridge of the spine using a centimeter strip. The data was processed using statistical analysis programs Microsoft Excel 2016 and IBM SPSS Statistics 25.

Results: a decrease in motion amplitude asymmetry was observed only after the dynamic exercise program $(\mathrm{p}<0.001)$. In the group of dynamic exercises, the asymmetry of muscle activity decreased only in the Mid-trapezius muscle $(p<0.05)$, and in the group of static exercises with biological feedback, the difference in muscle activity decreased in the Mid-trapezius and Gluteus Maximus muscles. The program of static exercises, with biological feedback, reduced the imbalance of the oxygen level of the Gluteus Maximus muscles more than the program of dynamic exercises $(p<0.001)$.

Conclusions: The program of dynamic physiotherapy exercises had a significant effect on the reduction of asymmetry of movement amplitudes. The methodology of static physiotherapy exercises with biological feedback increased the total muscle activity more and reduced the asymmetry of muscle activity more than the dynamic physiotherapy exercises. The methodology of static physiotherapy exercises with biological feedback reduced the imbalance of muscle aerobic metabolism between the left and right sides of the muscle more than the use of dynamic physiotherapy exercises.

Correspondence to: ruta.dadeliene@mf.vu.1t

Gauta 2021-03-05 